\title{
Avian Analysis of LCTA Special Use Plot Data: West Point Military Academy
}

by

Eric R. Schreiber and Alison Hill

The Land Condition Trend Analysis (LCTA) program is the Army's standard for land inventory and monitoring, using standardized methods of natural resources data collection, analyses, and reporting designed to meet multiple goals and objectives. This report presents the results of a study done for West Point in conjunction with the Army Environmental Center's (AEC) Conservation Assistance Program
(CAP). Four years of bird data were analyzed for LCTA special use plots during 1992, and 1995 through 1997. The information and techniques presented in this report are intended to provide land managers the ability to more effectively use the LCTA special use plot bird data being collected on their installation. 


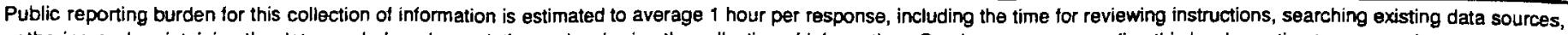

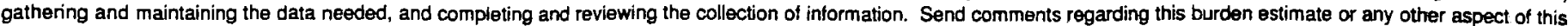

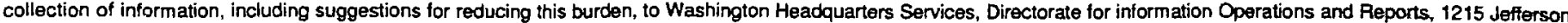
Davis Highway, Suite 1204, Arlington, VA 22202-4302, and to the Office of Management and Budget, Paperwork Reduction Project (0704-0188). Washington, DC 20503.

\begin{tabular}{|l|l|l}
\hline 1. AGENCY USE ONLY (Leave Blank) & $\begin{array}{c}\text { 2. REPORT DATE } \\
\text { August } 1998\end{array}$ & $\begin{array}{c}\text { 3. REPORT TYPE AND DATES COVERED } \\
\text { Final }\end{array}$
\end{tabular}

4. TITLE AND SUBTITLE $\quad$ 5. FUNDING NUMBERS

Avian Analysis of LCTA Special Use Plot Data: West Point Military Academy $\quad$ MIPR

W81EWF80489293

CAP 0697996-003

6. AUTHOR(S)

Eric R. Schreiber and Alison Hill

7. PERFORMING ORGANIZATION NAME(S) AND ADDRESS(ES)

U.S. Army Construction Engineering Research Laboratories (USACERL)

P.O. Box 9005

Champaign, IL 61826-9005

8. PERFORMING ORGANIZATION

REPORT NUMBER

SR $98 / 107$

9. SPONSORING / MONITORING AGENCY NAME(S) AND ADDRESS(ES)

Natural Resources Branch ITAM Program Manager

ATTN: DHPW

U.S. Military Academy

West Point, NY 10996

11. SUPPLEMENTARY NOTES

Copies are available from the National Technical Information Service, 5285 Port Royal Road, Springfield, VA 22161.

12a. DISTRIBUTION / AVAILABILITY STATEMENT

12b. DISTRIBUTION CODE

Approved for public release; distribution is unlimited.

13. ABSTRACT (Maximum 200 words)

The Land Condition Trend Analysis (LCTA) program is the Army's standard for land inventory and monitoring, using standardized methods of natural resources data collection, analyses, and reporting designed to meet multiple goals and objectives. This report presents the results of a study done for West Point in conjunction with the Army Environmental Center's (AEC) Conservation Assistance Program (CAP). Four years of bird data were analyzed for LCTA special use plots during 1992, and 1995 through 1997. The information and techniques presented in this report are intended to provide land managers the ability to more effectively use the LCTA special use plot bird data being collected on their installation.

\begin{tabular}{|c|c|c|c|}
\hline \multirow{2}{*}{$\begin{array}{l}\text { 14. SUBJECT TERMS } \\
\text { LCTA } \\
\text { Birds } \\
\text { Natural resource management }\end{array}$} & \multirow{2}{*}{\multicolumn{2}{|c|}{$\begin{array}{l}\text { West Point Military Academy } \\
\text { ecological surveys }\end{array}$}} & \multirow{2}{*}{$\begin{array}{l}\text { 15. NUMBER OF PAGES } \\
112 \\
\text { 16. PRICE CODE }\end{array}$} \\
\hline & & & \\
\hline $\begin{array}{l}\text { 17. SECURITY CLASSIFICATION } \\
\text { OF REPORT } \\
\text { Unclassified }\end{array}$ & $\begin{array}{l}\text { 18. SECURITY CLASSIFICATION } \\
\text { OF THIS PAGE } \\
\text { Unclassified }\end{array}$ & $\begin{array}{l}\text { 19. SECURITY CLASSIFICATION } \\
\text { OF ABSTRACT } \\
\text { Unclassified }\end{array}$ & $\begin{array}{l}\text { 20. LIMITATION OF } \\
\text { ABSTRACT } \\
\text { SAR }\end{array}$ \\
\hline
\end{tabular}




\section{Foreword}

This study was conducted for the U.S. Military Academy (USMA), West Point Environmental Office, Natural Resources Branch, under Military Interdepartmental Purchase Request (MIPR) No. W81EWF80489293 and the Conservation Assistance Program (CAP) tracking number 0697996-003. The technical monitor was Ms. Catherine Coleman, DHPW.

The work was performed by the Natural Resource Assessment and Management Division (LL-N) of the Land Management Laboratory (LL), U.S. Army Construction Engineering Research Laboratories (USACERL). The USACERL principal investigator was Dr. Alison Hill. Dr. John T. Bandy is Acting Operations Chief, CECER-LL. Dr. William D. Severinghaus is the responsible Technical Director. The USACERL technical editor was Gloria J. Wienke, Technical Resources.

COL James A. Walter is Commander and Dr. Michael J. O'Connor is Director of USACERL. 


\section{Contents}

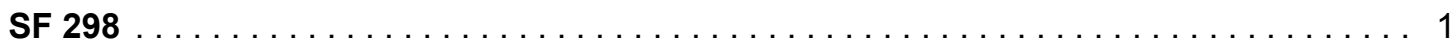

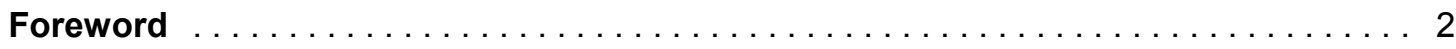

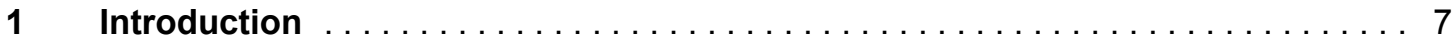

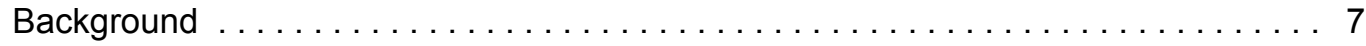

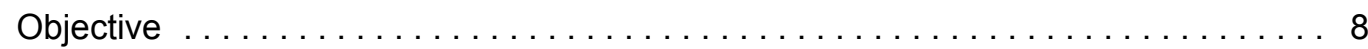

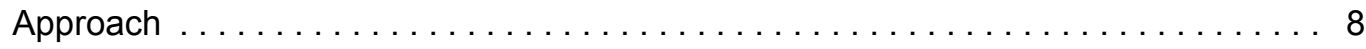

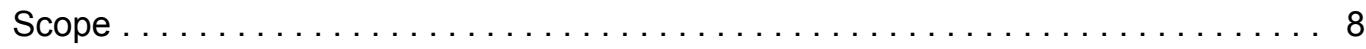

Mode of Technology Transfer $\ldots \ldots \ldots \ldots \ldots \ldots \ldots \ldots \ldots \ldots \ldots \ldots$

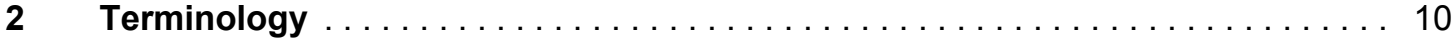

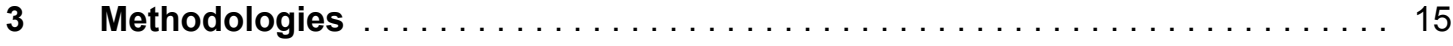

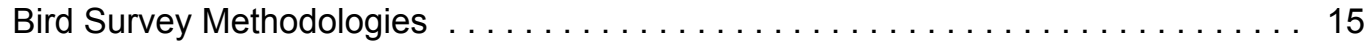

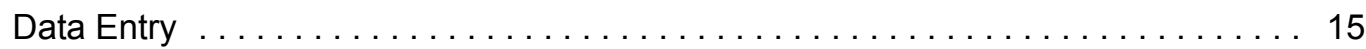

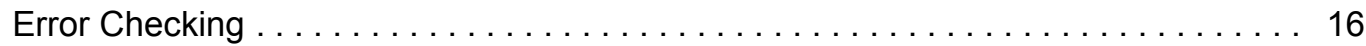

$4 \quad$ West Point Special Use Plot Summary Data $\ldots \ldots \ldots \ldots \ldots \ldots \ldots \ldots \ldots$

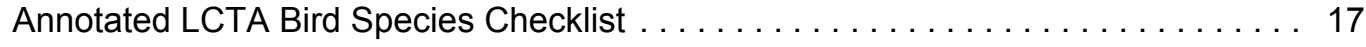

LCTA Plots Associated With Each Bird Species . . . . . . . . . . . . . . . . . . 17

Bird Species Associated With Each LCTA Plot . . . . . . . . . . . . . . . . . . . 18

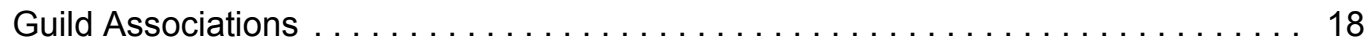

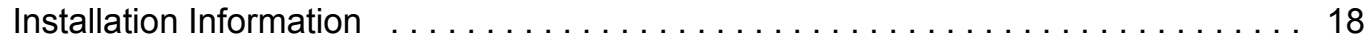

Installation Information by Vegetation Type $\ldots \ldots \ldots \ldots \ldots \ldots \ldots \ldots \ldots \ldots \ldots \ldots \ldots \ldots$

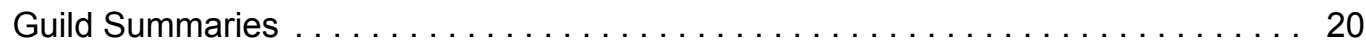

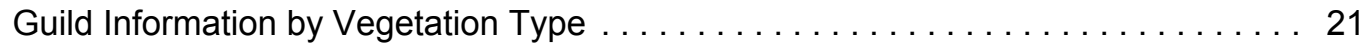

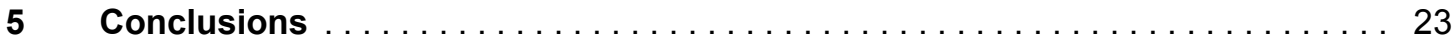

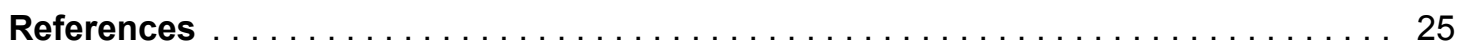

\section{Appendix A: West Point Species Checklist}

Table A. Annotated LCTA bird species checklist for West Point special use plots, with total number of birds per year 


\section{Appendix B: Plot Numbers for Each West Point Bird Species}

Table B. LCTA special use plot numbers associated with each West Point bird

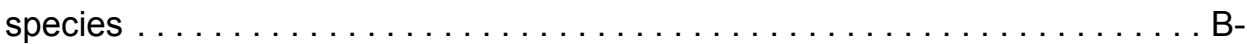

\section{Appendix C: West Point Bird Species on Each LCTA Plot}

Table C. Bird species checklist for West Point special use plots . . . . . . . . C-1

\section{Appendix D: Guild Associations for Each West Point Bird Species}

Table D. Guild association for each West Point bird species that occurs on

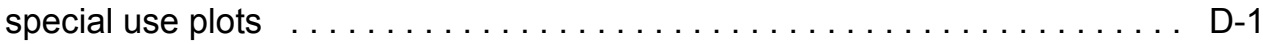

\section{Appendix E: West Point Summary Information}

Table E1. General information for West Point special use plot bird data . . . . . . E1-1 Table E2. Installation information for West Point special use plots, by year . . . . E E1-1 Table E3. Installation information for West Point special use plots, by period . . . E1-1 Table E4. Installation information for West Point special use plots, by transect . . E E4-4 Table E5. Installation information for West Point special use plots, by mated status E5-5

\section{Appendix F: West Point Summary Information by Vegetation Type}

Table F1. Vegetation types for West Point special use plots that were used in the analyses $\mathrm{F} 1-1$

Table F2. Installation summary for West Point special use plots, by vegetation typeF2-2 Table F3. Vegetation types for West Point special use plots, by year . . . . . . . . F3-1 Table F4. Vegetation types for West Point special use plots, by period . . . . . . F F-1 Table F5. Vegetation types for West Point special use plots, by transect . . . . . . F F-1 Table F6. Vegetation types for West Point special use plots, by mated status . . . . F6-1 Table F7. Vegetation types for West Point special use plots, by species . . . . . F7-1

\section{Appendix G: West Point Guild Summary Information}

Table G1. Guild summaries for West Point special use plots, by neotropical status G1-1 Table G2. Guild summaries for West Point special use plots, by nest location . . G G-1 Table G3. Guild summaries for West Point special use plots, by nest type . . . . . G3-1 Table G4. Guild summaries for West Point special use plots, by food type . . . . G4-1 Table G5. Guild summaries for West Point special use plots, by feeding substrate G5-1 Table G6. Guild summaries for West Point special use plots, by foraging techniqueG6-1 Table G7. Guild summaries for West Point special use plots, by habitat type . . G G-1

\section{Appendix H: West Point Guild Summary Information by Vegetation Type}

Table H1. Vegetation types for West Point special use plots, by neotropical status H1-1 Table H2. Vegetation types for West Point special use plots, by nest location . . . H2-1 Table H3. Vegetation types for West Point special use plots, by nest type . . . . . H3-1 Table H4. Vegetation types for West Point special use plots, by food type . . . . . H4-1 Table H5. Vegetation types for West Point special use plots, by feeding substrate H5-1 Table H6. Vegetation types for West Point special use plots, by foraging techniqueH6-1 Table H7. Vegetation types for West Point special use plots, by habitat type . . . H7-1 


\section{Introduction}

\section{Background}

The U.S. Army is currently responsible for managing 5 million hectares (12.4 million acres) on approximately 120 military installations throughout the United States. More than 50 military installations and training areas in the United States and Germany have implemented the Land Condition Trend Analysis (LCTA) program (Tazik et al. 1992).

The U.S. Army Construction Engineering Research Laboratories (USACERL) developed LCTA as a means to inventory and monitor natural resources on military installations. The LCTA program uses standardized methods of nature resource data collection, analysis, and reporting designed to meet the need for natural resources management and land stewardship (Tazik et al. 1992).

LCTA surveys use two types of plots: core and special use. Core plots are located in an objective, stratified manner to ensure that the data are representative of the installation (Warren et al. 1990). These plots are used to evaluate the condition of natural resources on the installation and serve as a basis for the national inventory. Special use plots are used for installation-specific issues that are not sufficiently covered by core plots. These plots can be allocated in any manner deemed appropriate by the installation, and are used to supplement baseline monitoring (Price et al. 1995).

The Environmental Office at West Point Military Academy began collecting LCTA special use plot data in 1992. However, only two plots (101 and 102) were sampled during that year. In 1995, nine additional special plots were allocated and Plot 102 was eliminated. Plots 101, and 103 through 111 have been sampled annually since 1995. West Point is unique in that one individual, Mr. Tom Miller, collected all the bird data from the LCTA core and special use plots.

Ms. Catherine Coleman of the Environmental Office at West Point contacted Mr. Steve Getlein, the Conservation Assistance Program (CAP) manager, at the U.S. Army Environmental Center, and submitted CAP requests for assistance with analyzing their LCTA bird data. West Point had particular interest in obtaining 
general trend information on the stability of the local bird populations. The first CAP request analyzed bird data from LCTA core plots and is summarized in Schreiber and Hill (1998). The second request analyzed the bird data from the LCTA special use plots and is summarized in this report.

\section{Objective}

The objective of this report was to produce summary tables of West Point's bird data from their LCTA special use plots.

\section{Approach}

Once the project was assigned on 5 March 1998, the USACERL and West Point investigators held a conference call to discuss the work and come to agreement on the desired product: a report containing digital summary tables of the LCTA special use plot bird data. The following tasks were completed in response to West Point's CAP request:

(1) Verified and fixed all errors within the 1992, and 1995 - 1997 bird data.

(2) Entered the revised bird data into Quest for analysis.

(3) Analyzed West Point's special use plot bird data.

(4) Provided West Point specific guild information regarding their special use plot bird species.

(5) Prepared a Final report for West Point.

(6) Sent West Point electronic files of the revised data and output and a hard copy of the final report.

\section{Scope}

This report summarizes West Point's bird data collected by using documented LCTA data collection techniques. It provides summaries of LCTA special use plot data from 1992, and 1995 through 1997.

\section{Mode of Technology Transfer}

West Point can use the compiled summary tables to support land management decisionmaking and to support the required documentation. This documentation includes, but is not limited to annual installation reports, the Integrated Natural 
Resource Management Plan (INRMP), and National Environmental Policy Act (NEPA) documents. All electronic files of the raw and compiled data will be transferred to West Point. 


\section{Terminology}

The variables used in the summary tables are defined below.

Ave FO birds - The average number of flyovers for each LCTA plot.

Ave site birds - The average number of birds recorded within the confines of the LCTA plot boundary.

Ave tot birds - The average number of birds recorded for each LCTA plot; includes both flyover and site species.

Distinct species - The term distinct species is synonymous with unique species. A total of 83 distinct onsite species were identified on West Point LCTA special use plots.

FO birds - Flyovers are birds that were observed outside the designated LCTA plot boundary.

FO plots - The number of LCTA plots in which flyover species were recorded outside the plot boundary or flying overhead.

Occurrence - Occurrence refers to each time a species was recorded on an LCTA plot. There was a total of 1,184 individual species occurrences, including flyovers, for all West Point LCTA special use plots.

Period - Time of day in which the survey was conducted.

AM - morning

PM - evening

Plotid - The plot number associated with each West Point LCTA wildlife plot.

Site birds - The total number of birds identified within the LCTA plot boundary.

Site plots - The total number of LCTA plots on which species were recorded. 
Total birds - The total number of birds recorded on West Point LCTA plots; includes both flyovers and site species.

Transect - Portion of the line transect in which species were recorded.

Line Out - Starting at the $0 \mathrm{~m}$ of the transect and walking to the $100 \mathrm{~m}$ end. End Point - The end of the 100-m transect.

Line In - Walking from the end point back to the $0 \mathrm{~m}$ point.

Vertid - LCTA wildlife codes were established in 1991 by researchers from USACERL (Kowalski and Whitworth 1991) and based on the scientific names from the 1987 Checklist of Vertebrates (Banks, McDiarmid, and Gardner 1987). Each code consists of the first two letters of the genus and the first two letters of the specific epithet. If duplicate codes exist, ascending numbers, starting with 1 , follow the four-letter code.

The following variables were used in the tables to describe guild information for the 83 distinct West Point bird species identified on LCTA special use plots.

Food type - The primary food eaten by West Point birds.

- Aquatic Inverts - Includes aquatic insects, crayfish, shrimp, snails, bivalves, etc.

- Fruit - Includes fruit and berries.

- Greens - May include leafy parts of both aquatic and terrestrial plants, and bulbs.

- Insects - May include insects, spiders, mites, land snails, slugs, worms, millipedes, sowbugs, etc.

- Seeds - Includes grains, sunflower seeds, conifer seeds, etc.

- Small Mammals - Any animal of the class Mammalia. Includes shrews, ground squirrels, rabbits, but most often rodents.

General Habitat - General habitat is a category that is often quite difficult to quantify. Many species frequent several habitat types and are not confined to just one. Therefore, habitat classifications within the database should be viewed cautiously.

- Forest - An extensive concentration of trees and related vegetation. Includes sparsely wooded areas, densely wooded areas, and pinon-juniper associations.

- Forest Edge - The transitional area where a forest ends and another distinct habitat begins.

- Freshwater - Includes areas such as lakes, ponds, rivers, and streams. 
- Grassland - An area of land on which the natural dominant plant forms are grasses and forbs. Areas with scattered trees and/or snags are included in this community type.

- Riparian - An area located along the bank of a natural watercourse (as a river) or sometimes of a lake or tidewater.

- Shoreline - The strip of land where a body of water and the shore meet.

- Shrubland - An area of land on which the natural dominant plant forms are shrubs (a low, usually several-stemmed woody plant).

- Swamp/Marsh - A wet, spongy land, saturated and sometimes partially or intermittently covered with water. Also includes tracts of soft, wet land, typically characterized by grasses and cattails.

Mated status - The categories used to describe the mated status of West Point bird species.

- Female only

- Flock

- Non-singing male

- Not recorded

- Pair (adult male and female)

- Singing male

- Unknown sex

Neo status - Neotropical migrant status of West Point species based on the following classification system (Partners in Flight 1991).

A "True" neotropical migrants; breed in North America and winter south of the United States.

B Generally breed and winter in North America, but some populations winter south of the United States.

R Resident species (i.e., non-neotropical migrant species).

Nest location - The location where West Point bird species nest.

- Ground - Includes nests placed among the roots, or in niches among the roots of fallen trees, among tules and reeds (in marshes), among grasses, on bare rock, or simply scraped in the dirt or sand.

- Man-made Structure - Includes nests placed among any man-made structure (bridge, barn, etc.).

- Reed - Nest built within and attached to reeds.

- Shrub - Includes nests placed within any multi-stemmed woody plant that does not have a distinct single trunk extending several feet between the ground and the lowest branching point. 
- Snag - Includes nests placed in a standing dead tree. Also used for species that use cavities in dead and live trees more/less indiscriminately.

- Woody Lower Canopy - Includes nests placed in the lower canopy of deciduous or coniferous trees.

- Woody Upper Canopy - Includes nests placed in the upper canopy of deciduous or coniferous trees.

Nest type - The type of nest that is constructed by West Point bird species.

- Cavity - Eggs placed in a cavity that has been excavated (woodpeckers) or in a natural cavity found in a dead or dying tree. Sometimes a cup or other structure is built within.

- Cup - A sometimes bulky, but always deep depression, with a hemispherical inside and a rim height several times the diameter of the eggs.

- Oven - Oven-shaped (roofed or arched) nest on the ground.

- Parasitic - No nest is constructed. Eggs are deposited in the nest of another species.

- Pendant - An elongate saclike nest suspended from a branch.

- Platform - A structure in a tree, on a cliff, or providing a dry place above marshy ground or water, usually big enough for the bird to land on, with or without a distinct depression to hold the eggs. Typical of many raptors and wetland birds.

- Saucer - A shallow cup with the height of the rim not more than twice the diameter of the eggs. Also a flattened nest of pliable vegetation as used by some wetland birds.

- Scrape - A simple depression usually with a rim sufficient to prevent eggs from rolling away. The scrape nest of many duck species are almost bowlshaped. Occasionally with lining added.

Substrate - The location where West Point bird species feed.

- Air - Foraging done in the air. Includes foraging techniques such as: Aerial Foraging, Aerial Pursuit, Hawker, Hover \& Pick, Hover Gleaner, and Piracy.

- Bark - Foraging done primarily on the bark of trees. Includes: Bark Gleaner.

- Foliage - Foraging done primarily on foliage. Includes: Foliage Browser and Foliage Gleaner.

- Ground - Foraging done primarily on the ground. Includes: Digging, Ground Gleaner, High Patrol, Hover \& Pounce, Low Patrol, Piracy, Scavenger, and Swooper.

- Water - Foraging done primarily on or in the water. Includes: Ambusher, Dabbler, High Dives, Prober, Skimmer, Surface Dips, and Surface Dives. 
Technique - The technique used by West Point bird species to obtain their food.

- Aerial Pursuit - Chasing or catching birds in midair, stooping (dropping on flying birds from above, killing them in midair with a blow from the talons), or snatching them from their perches.

- Bark Gleaner - Gleaning from tree trunks and branches. Includes excavating and drilling into bark.

- Dabbler - Floating on the surface in shallow water, pivoting headfirst downward while raising hind-quarters above the water to reach submerged plants or animals on or near the substrate.

- Foliage Browser - Browsing tender shoots, twigs, and leaves of trees and shrubs for food.

- Foliage Gleaner - Gleaning from foliage and occasionally from branches. Take invertebrates and/or fruit from the vegetation, not from the surface of the ground.

- Ground Gleaner - Picking up items from the surface of soil, turf, sand, etc.

- Hawker - Sallies from perch on short flights to capture flying insects.

- High Patrol - Soaring at high altitudes in search of carrion or prey.

- Hover Gleaner - Taking nectar, insects, or berries from plants above the ground while hovering.

- Low Patrol - Seeking prey in a low searching flight.

- Scavenger - Feeding on carrion, refuse, or material left unconsumed by other organisms.

- Surface Dives - Floating and then diving under water using feet and/or wings in search of prey.

- Swooper - Snatching prey from the ground in talons after a gliding descent from perch with wings spread. 


\section{Methodologies}

The bird data used in this analysis was collected from West Point LCTA special use plots during the 1992, and 1995 through 1997 field seasons by Mr. Tom Miller, research specialist. Survey methodologies followed similar LCTA protocols (Tazik et al. 1992).

\section{Bird Survey Methodologies}

LCTA special use plots can be allocated in any manner deemed appropriate by the installation, but generally follow the modified point-count technique, as used when sampling core plots. Each plot is surveyed once in the morning and once in the evening by slowly walking the 100-m transect in 6 minutes and recording all birds seen and heard within $100 \mathrm{~m}$ of the plot (Line Out). Upon reaching the end of the transect, the observer stops and records all birds seen and heard for 8 minutes within $100 \mathrm{~m}$ of the end (End Point). The observer then walks another 6 minutes back to the starting point, again recording all birds seen and heard within $100 \mathrm{~m}$ of the plot (Line In). Species observed outside the plot limits and flyover species are also recorded on the standard LCTA Bird Survey Data Form.

Surveys are typically conducted on relatively calm, rainless days, within a 2 - to 4 -week period that corresponds to the breeding season. Morning surveys are conducted between $1 / 2$ hour before and 4 hours after sunrise; evening surveys are conducted 4 hours before sunset. All birds observed, with common name, LCTA species code, and total number for each species are recorded within each segment of the survey, along with corresponding codes for mated status.

\section{Data Entry}

The 1992, and 1995 through 1997 special use plot bird data was entered into SQLBase format from standard LCTA paper data forms. 


\section{Error Checking}

The paper and electronic data files were checked for a number of common errors, which were corrected in the database. LCTA species codes were developed for all wildlife species, and should be used when collecting any LCTA-related data. However, errors may still arise. The various types of errors that may be encountered include: (1) entering an invalid species code (i.e., the species code does not correspond to a valid species, MYMU vs. HYMU), (2) entering the wrong species code for a particular species (i.e., the species code pertains to an entirely different species, VIOL vs. PIOL), (3) omitting the numerical value at the end of certain species codes (e.g., COVI vs. COVI1), or (4) entering an incorrect numerical value (e.g., SPPA1 vs. SPPA2).

Some errors can be fixed easily (e.g., correcting for invalid species codes); however, other errors involve cross-referencing back to the original data sheets and checking the species code against the common name. The species code must not only be correct, but legible, because the individual entering the data typically relies solely on the species code. Only when error-checking procedures are done, will the individual cross-reference the code to the common name, and correct for these inconsistencies. 


\section{West Point Special Use Plot Summary Data}

In 1992, only two special use plots (plots 101 and 102) were allocated. However, from 1995 through 1997, a total of ten special use plots were sampled annually. These include plots: 101, 103, 104, 105, 106, 107, 108, 109, 110, and 111. Plot 102 was not sampled after 1992.

\section{Annotated LCTA Bird Species Checklist}

Appendix A/Table A lists, by common name, the 83 distinct bird species recorded on West Point LCTA special use plots. The table includes the scientific name, LCTA code, and the total number of individuals recorded for each year. The Canada Goose had the most occurrences (63). However, the Canada Goose was only recorded from two plots during 1997, and should probably have been recorded as flyovers. The American Robin was the second most frequently observed species recorded on West Point special use plots, with 61 occurrences (5.4\%), followed by the Scarlet Tanager with $5.2 \%$ of the total occurrences, and the Red-eyed Vireo with $4.8 \%$ of the total occurrences.

Nine species were identified on special use plots that were not recorded from core plot data (Schreiber and Hill 1998). These species include: Bobolink (6 occurrences), European Starling (5 occurrences), Great Blue Heron (2 occurrences), Fish Crow (1 occurrence), Alder Flycatcher (1 occurrence), Eastern Meadowlark (1 occurrence), Great Horned Owl (1 occurrence), Tennessee Warbler (1 occurrence), and the American Woodcock (1 occurrence).

\section{LCTA Plots Associated With Each Bird Species}

Appendix B/Table B lists all LCTA special use plots in which a particular species was recorded, and the total number of individuals found on each plot. Several species were identified on all LCTA special use plots. These species include: Brown-headed Cowbird, Great-crested Flycatcher, and the Red-eyed Vireo. Additional species occurring on 10 of the 11 LCTA special use plots include Norther 
Flicker, Blue Jay, Eastern Wood Pewee, American Robin, Scarlet Tanager, Wood Thrush, Rufous-sided Towhee, and the Black-and-white Warbler.

\section{Bird Species Associated With Each LCTA Plot}

Appendix C/Table C lists all avian species recorded for each of the LCTA special use plots, and the total number of individuals for each species within that plot. The number of species recorded on individual plots ranged between 20 species (plot 102) and 47 species (plot 101), with the mean being 31 species per plot. However, plot 102 was sampled only in 1992, and was not sampled during 1995 through 1997.

\section{Guild Associations}

Appendix D/Table D contains generic guild information for the 83 West Point bird species that were identified on special use plots, with common name, scientific name, LCTA code, neotropical migrant status, nest location, nest type, food type, food substrate, feeding technique, and general habitat. This information was derived from a comprehensive list containing guild data for all bird species found within the United States (Schreiber and Whitworth 1998).

\section{Installation Information}

Table E1 in Appendix E lists the general information for West Point special use plot bird data. All (100\%) of the LCTA special use plots had species recorded within the plot boundary, while $63.6 \%$ had flyover species. In 1996, 1 Warbler and 1 Waterthrush were recorded, but not identified to the species level. Therefore, the number of site birds, and the number of occurrences will be slightly higher in 1996 than that reported in Tables A, B, C, and D, where these two individuals were excluded from analysis.

Table E2 is a similar division of the information presented in Table E1, except it presents the information by year. A total of 83 distinct species (1,137 occurrences) were recorded as site species. These include: 33 species (104 occurrences) in 1992, 63 species (288 occurrences) in 1995, 52 species (54 - 2 unknowns, 281 occurrences) in 1996, and 67 species (464 occurrences) in 1997.

Table E3 displays the installation information by year and period (i.e., time of day). The importance of dividing the information by period is to gain insight on which 
sampling time is best. Sampling in the morning clearly provides a much higher yield when looking at the average number of both total and site birds, within all years. However, generally speaking, time of day did not seem overly important when identifying flyover species.

Table E4 lists the installation information by transect. The data indicate that of the three transect segments (Line Out, End Point, and Line In), more species are being identified during the Line Out.

Table E5 lists the installation information by mated status. The singing male was the most frequently recorded category.

\section{Installation Information by Vegetation Type}

Vegetation types (Appendix F, Table F1) were derived from the New York Natural Heritage (NYNH) Communities map (Reschke 1990) and LCTA Plot Location map, created by West Point personnel. Information describing the ecological communities or West Point is contained in Schreiber and Hill (1998).

West Point's LCTA special use plots represent five vegetative categories. These categories include: Appalachian Oak-Hickory (5 plots), Burn Barren (1 plot), Hemlock-Hardwood Swamp (1 plot), Hemlock-Northern Hardwood Forest (1 plot), and Successional Old Field (3 plots) (Table F2). Most vegetative categories had very small sample sizes; subsequent analyses should be viewed with caution.

Table F3 lists the vegetation types for each year, with the total number of birds observed within each category.

Table F4 divides the vegetation types for each year, by period, with the total number of birds associated with each. With few exceptions, more birds were recorded in morning site counts than evening counts.

Table F5 divides the vegetation types by transect, with the total number of birds associated with each. With few exceptions, more birds were recorded during the Line Out than during the End Point or Line In, as evidenced in the average number of site birds.

Table F6 lists the vegetation types by mated status for each year, with the total number of birds associated with each. The singing male was the most frequently recorded category. 
Table F7 separates the West Point vegetation types by species recorded within each category. The number of species identified within each vegetative category is provided below. Small sample sizes should be viewed with caution.

Burn Barren - 25 species (1 plot)

Hemlock-Hardwood Swamp - 36 species (1 plot)

Hemlock-Northern Hardwood Forest- 38 species (1 plot)

Oak-Hickory - 59 species (5 plots)

Successional Old Field - 64 species (3 plots)

\section{Guild Summaries}

Information pertaining to the guild summary tables in Appendix $\mathrm{G}$ is based on a report by Schreiber and Whitworth (1998) that documents an LCTA database update that provides selected ecological attributes for 676 bird species occurring within the continental United States.

Table G1 lists the West Point bird species by neotropical status: Class A, Class B, and Resident species. A large percentage of birds that occur on West Point special use plots were identified as neotropical migrants. The annual percentages of neotropical migrant (Class A and Class B) species and species occurrences, are identified below.

\begin{tabular}{|c|c|c|}
\hline Year & $\begin{array}{c}\text { \% of species that } \\
\text { are migrants }\end{array}$ & $\begin{array}{c}\text { \% of species occurrences } \\
\text { that are migrants }\end{array}$ \\
\hline 1992 & 80.0 & 72.9 \\
\hline 1995 & 76.7 & 84.9 \\
\hline 1996 & 78.0 & 84.8 \\
\hline 1997 & 74.6 & 77.2 \\
\hline
\end{tabular}

Table G2 divides West Point's bird species into areas in which nesting occurs. Seven nesting locations were identified. Woody upper canopy nesters were the most common (32.2\%), followed by ground nesters (21.2\%), woody lower canopy nesters $(19.0 \%)$, and those nesting in shrubs (17.5\%).

Table G3 divides West Point's bird species by the type of nest that is constructed. Eight nest types were identified. According to the data, the majority of West Point birds make a cup-type nest (63.9\%), followed by cavity nesters $(12.4 \%)$. 
Table G4 lists the bird species by the types of foods used by each. Six food types were identified. According to the data, nearly $88.0 \%$ of the birds that were identified on West Point special use plots feed on insects.

Table G5 lists the bird species by feeding substrate categories. Five distinct feeding substrates were identified. According to the data, almost $41 \%$ of West Point bird species identified on special use plots, forage on the ground, followed by those that feed on foliage $(25.2 \%)$, and in the air $(20.0 \%)$.

Table G6 divides West Point's bird species by foraging technique categories. Thirteen foraging techniques have been identified from the birds occurring on West Point's special use plots. According to the data, the majority of birds were ground gleaners $(37.5 \%)$, foliage gleaners (15.9\%), and hover gleaners (12.5\%).

Table G7 lists the species by habitat types. Eight distinct habitat types have been identified from the birds occurring on West Point's special use plots. According to the data, the majority of birds preferred forested areas (58.2\%), forest edge (16.0\%), and shrubland areas (7.2\%).

\section{Guild Information by Vegetation Type}

Table H1 lists the vegetation types by neotropical migrant status. The overall percentage of neotropical migrant (Class A and Class B) species occurrences within each vegetation category are listed below.

Burn Barren - 85.5\%

Hemlock-Hardwood Swamp - 89.1\%

Hemlock-Northern Hardwood Forest - 84.5\%

Oak-Hickory - 82.3\%

Successional Old Field - 71.7\%

Table H2 lists West Point bird species by nest location, with the total number of individuals within each vegetation type, by year.

Table H3 lists the bird species by nest type, with the total number of individuals within each vegetation type, by year.

Table H4 lists the bird species, by food type, with the total number of individuals within each vegetation category, by year. 
Table H5 summarizes the bird species, by feeding substrate, with the total number of individuals within each vegetation category, by year.

Table H6 summarizes West Point bird species, by foraging technique, with the total number of individuals within each vegetation category, by year.

Table H7 summarizes West Point bird species, by habitat type, with the total number of individuals within each vegetation category, by year. 


\section{Conclusions}

A total of 83 avian species (1,137 occurrences) were identified at the U.S. Military Academy during the summers of 1992, and 1995 through 1997, from LCTA special use plots. The total number of species and occurrences, by year, are as follows: 33 species (104 occurrences) in 1992, 63 species (288 occurrences) in 1995, 54 species (281 occurrences) in 1996, and 67 species (464 occurrences) in 1997.

Nine species were identified on special use plots that were not recorded from core plots. These species include: Bobolink, European Starling, Great Blue Heron, Fish Crow, Alder Flycatcher, Eastern Meadowlark, Great Horned Owl, Tennessee Warbler, and the American Woodcock.

Regarding overall numbers, the Canada Goose was the most frequently observed species on West Point special use plots, with 63 occurrences (5.5\%), followed by the American Robin (5.4\%), Scarlet Tanager (5.2\%), and the Red-eyed Vireo (4.8\%).

The number of species recorded on individual plots ranged between 20 species (plot 102) and 47 species (plot 101), with the average being 31 species per plot. However, plot 102 was sampled only in 1992. Species identified on all special use plots include: Brown-headed Cowbird, Great-crested Flycatcher, and the Red-eyed Vireo.

Five vegetative categories were recognized from LCTA special use plots on West Point. These include: Appalachian Oak-Hickory, Burn Barren, Hemlock-Hardwood Swamp, Hemlock-Northern Hardwood Forest, and Successional Old Field.

Approximately $72.3 \%$ of the species identified from West Point special use plots are categorized as neotropical migrants (Class A and Class B), while 27.7\% are considered Resident species. The percentage of neotropical migrants per year ranged between $76.7 \%$ in 1995 to $80.0 \%$ in 1992 .

Guild summaries by nesting location, nest type, food type, foraging substrate, foraging technique, and habitat type for bird species occurring on LCTA special use plots are as follows. Of the seven nesting locations, most species nested in the woody upper canopy $(32.2 \%)$, on the ground $(21.2 \%)$, in the woody lower canopy $(19.0 \%)$, or in shrubs $(17.5 \%)$. Of the eight nest types, the majority of birds make 
a cup-type nest (63.9\%), or a cavity nest (12.4\%). Of the six food types used, nearly $88 \%$ of all species fed on insects. Of the five feeding substrates, nearly $41 \%$ of all species fed on the ground, on foliage $(25.2 \%)$, or in air $(20.0 \%)$. Of the thirteen foraging techniques, most species were ground gleaners $(37.5 \%)$, foliage gleaners $(15.9 \%)$, or hover gleaners $(12.5 \%)$. Of the eight habitat types, most species preferred forested areas $(58.2 \%)$, forest edge (16.0\%), or shrubland areas $(7.2 \%)$. 


\section{References}

Banks, R.C., R.W. McDiarmid, and A.L. Gardner. 1987. Checklist of Vertebrates of the United States, the U.S. Territories, and Canada. U.S. Fish and Wildlife Service, Resource Publication 166.

Partners in Flight. 1991. Annual Report (Information and Education Working Group and the National Fish and Wildlife Foundation, Washington, DC), vol. 2, no. 1.

Kowalski, D.G. and W.R. Whitworth. 1991. LCTA species code database developed by the United States Army Construction Engineering Research Laboratories.

Price, D.L., A.B. Anderson, W.R. Whitworth, and P.J. Guertin, Land Condition Trend Analysis Data Summaries, Technical Report 95/39 (USACERL, September 1995).

Reschke, C. 1990. Ecological Communities of New York State. New York Natural Heritage Program, New York State Department of Environmental Conservation.

Schreiber, E.R. and A. Hill, Avian Analysis of LCTA Core Plot Data: West Point Military Academy, Technical Report 98/102 (USACERL, July 1998).

Schreiber, E.R. and W.R. Whitworth, Land Condition Trend Analysis Avian Database: Ecological Guild-based Summaries, Technical Report 98/100 (USACERL, August 1998).

Tazik, D.J., S.D. Warren, V.E. Diersing, R.B. Shaw, R.J. Brozka, C.F. Bagley, and W.R. Whitworth, U.S. Army Land Condition-Trend Analysis (LCTA) Plot Inventory Field Methods, Technical Report N-92/03/ADA247931 (USACERL, February 1992).

Warren, S.D., M.O. Johnson, W.D. Goran, and V.E. Diersing, "An Automated, Objective Procedure for Selecting Representative Field Sample Sites," Photogrammetric Engineering and Remote Sensing, Vol. 56, No. 3 (1990) pp. 333-335. 
Appendix A: West Point Species Checklist 


\section{Appendix B: Plot Numbers for Each West Point Bird Species}


Appendix C: West Point Bird Species on Each LCTA Plot 


\section{Appendix D: Guild Associations for Each West Point Bird Species}




\section{Appendix E: West Point Summary Information}




\section{Appendix F: West Point Summary Information by Vegetation Type}




\section{Appendix G: West Point Guild Summary Information}




\section{Appendix H: West Point Guild Summary Information by Vegetation Type}

